\title{
META-ANALISIS PENGGUNAAN BAHAN AJAR TERHADAP PRESTASI MATEMATIKA
}

\author{
Gusti Ayu Dessy Sugiharni ${ }^{1)}$ dan I Wayan Kayun Suwastika ${ }^{2)}$ \\ ${ }^{1,2}$ Sistem Informasi, Institut Teknologi dan Bisnis STIKOM Bali \\ ${ }^{1,2}$ Jl. Raya Puputan No. 86 Renon, Denpasar-Bali, 80118 \\ E-mail : ayu_dessy@stikom-bali.ac.id ${ }^{1)}$, kayun_suwastika@stikom-bali.ac.id ${ }^{2)}$
}

\begin{abstract}
ABSTRAK
Penggunaan bahan ajar yang efektif dianggap sebagai aspek penting dari kurikulum matematika yang baru dikembangkan dalam menghadapi situasi pandemi Covid-19. Studi penggunaan bahan ajar yang memiliki impak dalam pembelajaran matematika yang mengungkapkan berbagai manfaat bagi siswa telah banyak dilakukan para peneliti. Penelitian ini bertujuan untuk mengetahui pengaruh semua bentuk bahan ajar matematika yang digunakan terhadap prestasi akademik siswa. Studi meta-analisis ini termasuk penelitian empiris tentang penggunaan bahan ajar matematika. Penelitian ini membahas kesenjangan dalam literatur dengan memeriksa efisiensi pembelajaran relatif dari beberapa bentuk bahan ajar. Selain itu, penelitian ini membahas sejauh mana penggunaan bahan ajar dalam pembelajaran matematika dan variabel moderator yang mempengaruhi penggunaan bahan ajar matematika dijelaskan secara rinci. Tujuan utama dari penelitian ini adalah untuk mengetahui pengaruh pembelajaran matematika dengan pendayagunaan bahan ajar terhadap prestasi siswa, dengan menganalisis penelitian yang diterbitkan antara tahun 2016 sampai dengan 2021. 27 hasil penelitian yang telah dipublikasikan antara tahun 2016-2020 dimasukkan dalam meta-analisis dan dihitung effect size dari masing-masing penelitian. Penggunaan bahan ajar dalam pembelajaran matematika memiliki pengaruh yang positif dan tinggi terhadap prestasi belajar. Berdasarkan analisis variabel mediator yang berkaitan dengan karakteristik instruksional, terdapat perbedaan yang signifikan pada variabel jenis prestasi matematika, jenis bahan ajar, dan metode penggunaan bahan ajar. Akan tetapi variabel moderator yang terkait dengan karakteristik metodologi tidak memiliki pengaruh moderasi yang signifikan terhadap prestasi belajar.
\end{abstract}

Kata Kunci: Efek, Bahan Ajar, Prestasi, Matematika, Meta-Analisis

\section{PENDAHULUAN}

Keterlibatan siswa secara aktif dengan suatu bahan ajar berpengaruh pada cara siswa membangun pengetahuannya yang semakin kompleks (Miller dkk, 2017). Pendayagunaan beragam jenis perlengkapan adalah penting dalam pendidikan maupun bidang lainnya untuk menanggapi hal ini. Saat kurikulum dan buku teks nasional ditinjau, setidaknya terlihat bahwa ada kegiatan yang terkait dengan setiap tujuan pembelajaran, sehingga bahan ajar yang sesuai disarankan untuk digunakan guru dalam pengajaran matematika terkait dengan setiap kegiatan pembelajaran (Sentürk \& Zeybek, 2019). Pada konteks ini pemanfaatan bahan ajar yang berbasis teknologi informasi adalah bahan ajar yang efektif dan dianggap sebagai aspek penting dari kurikulum matematika yang baru dikembangkan dalam menghadapi situasi pandemi Covid-19 (Zwart dkk, 2017). Penelitian terdahulu yang meneliti tentang penggunaan bahan ajar dalam pembelajaran matematika mengungkapkan manfaat yang bervariasi bagi siswa (Baist dkk, 2019; Moraová, 2017; Mutmainah dkk, 2019; Zwart dkk, 2017). Misalnya, pemanfaatan bahan ajar dalam pembelajaran matematika secara khusus untuk mengembangkan keterampilan psikomotorik. Adapun NCTM menerbitkan laporan pada tahun 2000 yang menganjurkan bahwa siswa harus diberikan akses langsung dengan bahan ajar agar mereka dapat membangun pemahaman mendasar mereka terhadap matematika. Pengadopsian student-centred dan mengintegrasikan bahan ajar kedalam lingkungan belajar adalah suatu efisiensi bagi guru dalam proses pembelajaran (Alshehri \& Ali, 2016). Penggunaan bahan ajar dalam pembelajaran matematika merupakan hal penting yang digunakan untuk mengonkretkan konsep dan hubungan. Pemanfaatan bahan ajar dalam pembelajaran terbukti menjadi pendukung pembelajaran yang efektif untuk meningkatkan keberhasilan siswa dalam pembelajaran matematika (Ng \& Chan, 2018). Penggunaan model pembelajaran dan didukung oleh bahan ajar yang tepat sangat diperlukan dalam pengajaran konsep matematika abstrak (Arthur-Nyarko dkk, 2020). Dengan bantuan bahan ajar, siswa mengembangkan sikap positif terhadap pembelajaran dan guru membangkitkan minat mereka, menguatkan keaktifan mereka dalam berpartisipasi dan meningkatkan keterampilan pemecahan masalah mereka (Kreijns dkk, 2017). Melakukan kolaborasi dari variasi bahan ajar dapat menunjang untuk mencakup konsep matematika dari yang sederhana sampai yang rumit dan dari konkret ke abstrak (Mughaz dkk, 2020). Sehingga bahan ajar 
merupakan salah satu pendukung yang penting dalam pendidikan dimana siswa dapat mempelajari matematika secara bermakna dan mencitrakan konsep abstrak secara optis. Siswa dapat membangun pengetahuan matematis dalam lingkungan belajar yang konsep matematikanya direpresentasikan dengan model yang bervariasi (Park, 2019). Konsep ini juga dapat di intepretasikan oleh siswa dengan pengetahuan dan pengalaman yang mereka miliki sebelumnya. Sangat penting untuk siswa membangun pengetahuan matematikanya sendiri saat mereka memaknai berbagai hal yang dilakukannya dengan lebih mudah. Akan tetapi, berbagai masalah praktis dan pedagogis yang terkait dengan pendayagunaan bahan ajar selama pembelajaran menjadi kesulitan bagi guru untuk keefektifan penerapannya (Ünlü, 2017).

Pembelajaran matematika adalah suatu objek yang dapat memaknai secara individu oleh seseorang dengan bantuan indra nya dimana secara sadar maupun tidak sadar pemahaman matematika akan terpupuk (Kontaş, 2016). Oleh karena itu, bahan ajar digital adalah bahan ajar berbasis teknologi informasi yang dapat dimanfaatkan siswa untuk mempelajari ide-ide matematikanya (Demirkan, 2019). Bahan ajar digital ini dapat diakses secara online. Ketika akses internet tersebar di sekolah maka bahan ajar digital akan menjadi lebih mudah untuk diakses. Bahan ajar digital memungkinkan guru untuk lebih mudah mencocokkan citra bergambar, verbal, dan simbolik dari masalah matematika (Karakırık \& Aydın, 2016). Mengajar dengan bahan ajar digital memberikan lebih banyak fleksibilitas dalam pembelajaran matematika (Basarmak, 2019). Bahan ajar dalam lingkungan berbasis web memberikan peluang untuk inter aktivitas siswa dan guru. Selain itu, ada kebutuhan untuk menggunakan teknologi informasi dalam pengajaran matematika sebagai bahan ajar (Nieto-Márquez dkk, 2020). Dalam hal ini, penting bagi siswa untuk menafsirkan konsep melalui pengalaman nyata dan konkrit. Pada penelitian Burns dan Hamm ditemukan beberapa studi yang mendukung gagasan bahwa bahan ajar digital harus digunakan lebih dari bahan ajar konkrit (Burns \& Hamm, 2011). Demikian pula, menurut Chen dan Shu, keuntungan menggunakan bahan ajar digital dari pada bahan ajar konkrit adalah bahan ajar berbasis teknologi mudah diakses dan bahan ajar berbasis teknologi juga mengasosiasikan simbol abstrak dengan gambar visual. Pemanfaatan teknologi dalam matematika berdampak positif terhadap kualitas belajar mengajar. Mengintegrasikan kegiatan pembelajaran dalam konteks yang sesuai juga mempengaruhi pembelajaran secara positif (Chen \& Su, 2019). Ada sejumlah besar penelitian yang diterbitkan dan menjelaskan pengaruh penggunaan bahan ajar dalam pembelajaran matematika terhadap prestasi akademik siswa. Sebagian besar penelitian ini telah menemukan bahwa menggunakan bahan ajar digital dalam pelajaran matematika memiliki kontribusi yang lebih positif terhadap pembelajaran siswa (Dewi dkk, 2019; Özcan \& Koştur, 2019; Rikkerink dkk, 2016;
Soykan dkk, 2019). Beberapa peneliti juga tidak menemukan pengaruh atau efek negatif penggunaan bahan ajar digital terhadap prestasi siswa dalam belajar matematika (Hornburg dkk, 2021; Moyer-Packenham \& Suh, 2012). Keberhasilan dalam pemanfaatan bahan ajar digital dipengaruhi oleh beberapa faktor. Misalnya, faktor-faktor seperti lamanya perlakuan, wawasan guru, jenis materi, tingkat usia siswa dan karakteristik lain dari lingkungan belajar akan berpengaruh terhadap proses pembelajaran.

Berdasarkan hal tersebut maka diperlukan pengulasan secara sistematis dari penelitian-penelitian yang telah tersedia tentang pendayagunaan bahan ajar dalam pembelajaran matematika.

\section{RUANG LINGKUP}

Ada banyak penelitian tentang efek penggunaan bahan ajar di lingkungan ruang kelas dan bahan ajar, dimana ini juga disarankan dalam kurikulum yang direvisi. Ada pula beberapa penelitian lain tentang keefektifan bahan ajar, hal ini menunjukkan kebutuhan untuk menggabungkan semua penelitian individual dan penelitian berkelompok ini dan menganalisisnya secara sistematis dalam satu penelitian. Sehingga penelitian tunggal ini akan memiliki kontribusi secara khusus dan unik. Penelitian ini bertujuan untuk mengetahui pengaruh semua bentuk bahan ajar matematika yang digunakan terhadap prestasi akademik siswa. Studi meta-analisis ini termasuk penelitian empiris tentang penggunaan bahan ajar matematika. Penelitian ini membahas kesenjangan dalam literatur dengan memeriksa efisiensi pembelajaran relatif dari beberapa bentuk bahan ajar. Selain itu, penelitian ini membahas sejauh mana penggunaan bahan ajar dalam pembelajaran matematika dan variabel moderator yang mempengaruhi penggunaan bahan ajar matematika dijelaskan secara rinci. Berkaitan dengan hal tersebut, maka penting bagi peneliti untuk mengetahui siapa yang memberikan pembelajaran kepada siswa, berapa lama pembelajaran tersebut berlangsung, bagaimana penerapannya, di jenjang pendidikan mana bahan ajar tersebut digunakan, jenis bahan ajar apa yang digunakan. Tujuan utama dari penelitian ini adalah untuk mengetahui pengaruh pembelajaran matematika dengan pendayagunaan bahan ajar terhadap prestasi siswa, dengan menganalisis penelitian yang diterbitkan antara tahun 2016 sampai dengan 2021. Alasan di baliknya adalah bahwa kurikulum matematika telah direvisi sesuai dengan pendekatan constructivist pada tahun 2013 di Indonesia. Sesuai dengan tujuan utama tersebut, maka dicari solusi untuk sub masalah berikut: Rata-rata penggunaan bahan ajar dalam pembelajaran matematika; Pengaruh rata-rata penggunaan bahan ajar matematika terhadap prestasi belajar siswa ditinjau dari karakteristik metodologi; Pengaruh rata-rata penggunaan bahan ajar matematika terhadap prestasi belajar siswa ditinjau dari karakteristik instruksional. 


\section{BAHAN DAN METODE}

Penelitian ini menggunakan metode meta-analisis untuk membuat review sistematis dan terintegrasi dari penelitian tentang penggunaan bahan ajar dalam pembelajaran matematika yang telah dipublikasikan. Meta-analisis adalah suatu metode penelitian yang merangkum hasil-hasil penelitian untuk menemukan solusi dari masalah yang sama dan memberikan hasil secara umum (Mavridis \& White, 2020). Sehingga untuk mengidentifikasi pola, metode ini memungkinkan kombinasi dan perbandingan banyak data statistik dari berbagai studi tentang topik tertentu (Samartsidis dkk, 2020). Ada tiga langkah yang harus dilakukan dalam proses pengumpulan data, agar dapat mengetahui pengaruh pemanfaatan bahan ajar yang digunakan dalam pembelajaran matematika terhadap prestasi akademik. Tiga langkah tersebut adalah literature review, criteria for research inclusion dan Coding Process (Lei dkk, 2020).

Literature review dilakukan secara sistematis untuk memilih penelitian yang akan dimasukkan dalam metaanalisis. Suatu cara dilakukan untuk mengakses semua penelitian yang telah dipublikasikan dan berfokus pada efek penggunaan bahan ajar dalam pembelajaran matematika pada prestasi siswa. Sejalan dengan tujuan penelitian maka dilakukan pencarian pada mesin pencari seperti Google Scholar, ERIC, Directory of Open Access Journal (DOAJ), Research gate, dan Freefullpdf pada Januari 2021. Menggunakan alat 'penelusuran lanjutan' dari basis data ini, publikasi ilmiah yang ditulis antara tahun 2016 sampai dengan tahun 2021 dideteksi berdasarkan judul, abstrak dan kata kunci. Kata kuncinya adalah sebagai berikut; 'teaching material, 'mathematic teaching material', dan 'digital teaching material'. Setelah tinjauan pustaka ekstensif, 101 publikasi ilmiah dipilih. Namun, 27 penelitian yang sesuai dengan tujuan penelitian telah diidentifikasi.

Setelah dilakukan tinjauan pustaka yang ekstensif mengenai penggunaan materi pendidikan dalam pendidikan matematika, peneliti menentukan kriteria untuk memilih penelitian tentang pengaruh penggunaan bahan ajar terhadap prestasi belajar siswa dalam pembelajaran matematika. Adapun beberapa kriteria inklusi dalam penelitian ini adalah: 1) Topik penelitian yang berisikan penelitian tentang bahan ajar matematika; 2) Tahun publikasi yaitu yang diterbitkan antara tahun 2016-2020; 3) Sampel yang terdiri dari jenjang SD(Sekolah Dasar), SMP (Sekolah Menengah Pertama), SMA/SMK(Sekolah Menegah Atas/Sekolah Menengah Kejuruan) dan Perguruan Tinggi; 4) Desain penelitian eksperimental yang berada dalam desain kelompok control post-test; 5) Investigasi keberhasilan siswa yaitu menganalisa keberhasilan siswa sebagai variabel terikat; 6) Investigasi penggunaan bahan ajar yaitu menganalisis pemanfaatan bahan ajar dalam pembelajaran matematika sebagai variabel bebas; 7) Memiliki data numerik yang memadai yaitu menyajikan data statistik untuk kelompok eksperimen dan kontrol seperti ukuran sampel, deviasi standar, dan nilai rata-rata aritmetika. Sesuai dengan kriteria inklusi, maka disusun berbagai kajian terkait penggunaan bahan ajar dalam pembelajaran matematika. Penelitian tanpa data statistik yang diperlukan dan penjelasan tentang variabel moderator tidak dimasukkan, hal ini dilakukan untuk memudahkan menghitung ukuran pengaruh. Penelitian meta-analisis ini meliputi penelitian empiris tentang penggunaan bahan ajar matematika.

Menyusun secara sistematik beberapa penelitian menurut karakteristiknya adalah merupakan suatu proses pengodean (Lei dkk, 2020). Pada tahap ini penelitian yang termasuk dalam meta analisis diberi kode melalui formulir coding yang disiapkan oleh peneliti. Penelitian yang menyelidiki pengaruh penggunaan bahan ajar pada keberhasilan siswa dalam matematika diberi kode dengan bantuan formulir pengodean ini. 27 dari 101 penelitian yang ditemukan dalam penelusuran literature dan memenuhi kriteria pada formulir pengodean dimasukkan dalam meta-analisis. Formulir pengodean yang digunakan dalam penelitian ini terdiri dari tiga bagian utama. Bagian pertama adalah "Identifikasi penelitian" yang berisi informasi tentang penelitian seperti 'tahun penelitian', 'judul penelitian' dan 'nama penulis'. Bagian kedua mencakup "Data penelitian" yang memiliki data statistik seperti nilai rata-rata dan deviasi standar kelompok eksperimen dan kontrol serta ukuran sampel. Bagian ketiga adalah "Karakteristik Isi Kajian" yang memuat informasi tentang isi kajian. Karakteristik yang terkait dengan isi penelitian dibagi menjadi dua kelompok yaitu metodologi dan instruksional. Berikut adalah penjelasan faktor-faktor yang menentukan karakteristik metodologi dan instruksional.

\section{1.Karakteristik Metodologi}

Terdapat beberapa karakteristik metodologi dijabarkan sebagai berikut:

1. Tahun publikasi: Penelitian tentang penggunaan bahan ajar matematika dalam pembelajaran yang diterbitkan antara tahun 2016 sampai dengan 2021 dimasukkan dalam penelitian. Hal ini karena penyajian 5 tahun terakhir 2016-2021 membuat hasil lebih jelas dan dapat dipahami.

2. Desain Penelitian: Penelitian yang dilakukan untuk mengetahui pengaruh pembelajaran matematika dengan memanfaatkan bahan ajar terhadap prestasi belajar siswa dikumpulkan dalam penelitian ini. Semua penelitian terpilih diklasifikasikan dan diberikan kode berdasarkan desain penelitian yang digunakan.

3. Kelompok Sampel: Kelompok sampel diberi kode seperti 'SD,'SMP, 'SMA/SMK' dan 'Perguruan Tinggi'.

4. Alat Pengukuran: Ukuran hasil diklasifikasikan sebagai instrumen penilaian yang dikembangkan peneliti atau standar yang ditemukan dalam literatur. Proses reliabilitas dan validitas dilakukan untuk kedua jenis instrumen tersebut. Ada juga peneliti yang dibantu oleh pertanyaan-pertanyaan dari 
instrumen penelitian lain yang memang sudah tersedia pada penelitian sebelumnya. Tabel 1 menggambarkan karakteristik metodologi dari 27 penelitian yang termasuk dalam meta-analisis dengan frekuensi dan nilai persentasenya.

Tabel 1. Nilai Frekuensi dan Persentase Karakteristik Metodologi

\begin{tabular}{|c|c|c|c|c|c|c|c|c|c|c|c|}
\hline \multicolumn{12}{|c|}{ Karakteristik } \\
\hline \multicolumn{3}{|c|}{ Tahun Publikasi } & \multicolumn{3}{|c|}{ Desain Penelitian } & \multicolumn{3}{|c|}{ Kelompok Sampel } & \multicolumn{3}{|c|}{ Alat Pengukuran } \\
\hline & $\mathbf{n}$ & $\%$ & & $\mathbf{n}$ & $\%$ & & $\mathbf{N}$ & $\%$ & & $\mathbf{n}$ & $\%$ \\
\hline 2016 & 2 & 7.41 & Pengembangan & 10 & 37.04 & SD & 7 & 25.93 & Dikembangkan & 22 & 81.48 \\
\hline 2017 & 4 & 14.81 & Eksperimen & 13 & 48.15 & SMP & 4 & 14.81 & Sudah ada & 5 & 18.52 \\
\hline 2018 & 3 & 11.11 & PTK & 3 & 11.11 & SMA/SMK & 5 & 18.52 & & & \\
\hline 2019 & 11 & 40.74 & Mix Method & 1 & 3.70 & Mahasiswa & 10 & 37.04 & & & \\
\hline 2020 & 7 & 25.93 & & & & Guru & 1 & 3.70 & & & \\
\hline Total & 27 & 100 & & 27 & 100 & & 27 & 100 & & 27 & 100 \\
\hline
\end{tabular}

Seperti yang dapat dilihat dari Tabel 1, penelitian yang termasuk dalam meta-analisis diklasifikasikan berdasarkan tahun penelitian, desain penelitian yang digunakan dalam penelitian, jenis pengambilan sampel yang digunakan dalam penelitian dan apakah instrument yang digunakan tersebut dikembangkan oleh peneliti atau menggunakan instrument yang sudah tersedia dari penelitian sebelumnya.

\section{2. Karakteristik Instruksional}

Berikut dijabarkan beberapa karakteristik

Instruksional

1. Jenis Prestasi Matematika: Pengodean diberikan terhadap jenis prestasi matematika siswa yang ditentukan dalam pelaksanaan penelitian.
2. Jenis Bahan Ajar: Bahan ajar matematika pada konteks ini ditemukan ada yang berbasis teknologi informasi (aplikasi computer) dan ada yang berbentuk fisik serta ada juga yang berbentuk fisik dan digital.

3. Pelaksana: Orang yang menggunakan bahan ajar dalam pembelajaran matematika dikodekan dalam tiga kategori berbeda yaitu 'guru', 'peneliti' dan 'guru dan peneliti'.

4. Metode penggunaan bahan ajar: Cara penggunaan bahan ajar matematika dikodekan dalam empat kategori berbeda yaitu 'individu', 'kelompok kecil', 'partisipasi penuh' dan campuran '.

Karakteristik instruksional dari 27 penelitian disajikan pada Tabel 2.

Tabel 2. Nilai Frekuensi Dan Persentase Karakteristik Instruksional

\begin{tabular}{|c|c|c|c|c|c|c|c|c|c|c|c|}
\hline \multicolumn{12}{|c|}{ Karakteristik } \\
\hline \multicolumn{3}{|c|}{ Jenis Prestasi Matematika } & \multicolumn{3}{|c|}{ Jenis Bahan Ajar } & \multicolumn{3}{|c|}{ Pelaksana } & \multicolumn{3}{|c|}{ Metode penggunaan bahan ajar } \\
\hline & $\mathbf{N}$ & $\%$ & & $\mathbf{n}$ & $\%$ & & $\mathbf{n}$ & $\%$ & & $\mathbf{n}$ & $\%$ \\
\hline $\begin{array}{l}\text { Keterampilan } \\
\text { berpikir }\end{array}$ & 4 & 14.81 & $\begin{array}{l}\text { Berbasis } \\
\text { Komputer }\end{array}$ & 17 & 62.96 & Dosen & 25 & 92.59 & Individual & 5 & 18.52 \\
\hline Hasil belajar & 18 & 66.67 & Pisik & 7 & 25.93 & Guru & 2 & 7.41 & Berkelompok & 7 & 25.93 \\
\hline $\begin{array}{l}\text { Pemecahan } \\
\text { masalah }\end{array}$ & 2 & 7.41 & $\begin{array}{c}\text { Pisik \& Berbasis } \\
\text { Komputer }\end{array}$ & 3 & 11.11 & & & & $\begin{array}{c}\text { Individual dan } \\
\text { berkelompok }\end{array}$ & 20 & 55.56 \\
\hline Pemahaman & 1 & 3.70 & & & & & & & & & \\
\hline Metakognitif & 1 & 3.70 & & & & & & & & & \\
\hline $\begin{array}{c}\text { Keterampilan } \\
\text { Komunikasi }\end{array}$ & 1 & 3.70 & & & & & & & & & \\
\hline Total & 27 & 100 & & 27 & 100 & & 27 & 100 & & 27 & 100 \\
\hline
\end{tabular}

\subsection{Analisis Data}

Analisis data dilakukan setelah pengodean pada formulir pengodean. Data yang dianalisis adalah data statistik dari penelitian yang termasuk dalam meta analisis tentang penggunaan bahan ajar. Pada penelitian ini untuk analisis data menggunakan metode metaanalisis effect size. Tujuan dasar keefektifan perlakuan dengan cara ini ditunjukkan menggunakan rumus $\mathrm{d}=$ (Xe-Xc) / SD (Gozuyesil \& Tanriseven, 2017). Nilai numerik yang diperoleh dalam penelitian diubah menjadi standar effect size untuk memastikan pengukuran ekuivalen terkait dengan standar deviasi setiap penelitian (Maggin dkk, 2019). Effect size juga ditentukan sesuai dengan jenis meta analisis yang digunakan (Kraft, 2020).
Pengaruh perlakuan menggunakan 'd' sebagai perwakilan dari standar effect size (Kraft \& Hattie, 2021). Perbedaan rata-rata digunakan untuk menghitung standar effect size dalam penelitian ini. Oleh karena itu, effect size ini sering dijelaskan dalam penelitian yang meneliti pengaruh variabel independen yang dimanipulasi pada variabel dependen kontinu. Ketika suatu statistik dalam sebuah penelitian tidak dinyatakan secara langsung maka nilai 'd Cohen' dihitung dari statistik deskriptif yang dilaporkan atau statistik $\mathrm{F}$ atau $\mathrm{t}$ yang diamati (Lorah, 2018). Kemudian hasilnya di kategori sesuai dengan klasifikasi effect size Cohen. 


\section{PEMBAHASAN}

Penelitian ini dilakukan untuk mengetahui pengaruh penggunaan bahan ajar dalam pembelajaran matematika terhadap prestasi akademik siswa. 27 effect size dari masing-masing penelitian digunakan secara total. Tabel 3 menunjukkan rata-rata effect size dari penelitian-penelitian yang termasuk ke dalam meta-analisis.

Tabel 3. Rata-Rata Effect Size Masing-Masing Penelitian.

\begin{tabular}{|c|c|c|c|}
\hline No. & Kode & Effect Size & Kategori \\
\hline 1 & BA01 & 0.4223 & Sedang \\
\hline 2 & BA02 & -0.7260 & Terjadi Penurunan \\
\hline 3 & BA03 & 0.1859 & Rendah \\
\hline 4 & BA04 & 1.0779 & Tinggi \\
\hline 5 & BA05 & -0.3506 & Terjadi Penurunan \\
\hline 6 & BA06 & 0.6273 & Sedang \\
\hline 7 & BA07 & 0.0173 & Rendah \\
\hline 8 & BA08 & 0.2539 & Rendah \\
\hline 9 & BA09 & 0.1034 & Rendah \\
\hline 10 & BA10 & 0.2698 & Rendah \\
\hline 11 & BA11 & 0.1966 & Rendah \\
\hline 12 & BA12 & 0.0704 & Rendah \\
\hline 13 & BA13 & 0.7822 & Tinggi \\
\hline 14 & BA14 & 0.0395 & Rendah \\
\hline 15 & BA15 & 0.7353 & Tinggi \\
\hline 16 & BA16 & 0.8186 & Tinggi \\
\hline 17 & BA17 & 0.5518 & Sedang \\
\hline 18 & BA18 & -0.3396 & Terjadi Penurunan \\
\hline 19 & BA19 & 0.5024 & Sedang \\
\hline 20 & BA20 & 0.4026 & Sedang \\
\hline 21 & BA21 & -1.5585 & Terjadi Penurunan \\
\hline 22 & BA22 & 0.7049 & Tinggi \\
\hline 23 & BA23 & 0.1306 & Rendah \\
\hline 24 & BA24 & 0.0807 & Rendah \\
\hline 25 & BA25 & 0.6269 & Sedang \\
\hline 26 & BA26 & 0.8100 & Tinggi \\
\hline 27 & BA27 & 0.4165 & Sedang \\
\hline \multicolumn{2}{|r|}{$\sum_{E S}$} & 6.8522 & \\
\hline \multicolumn{2}{|r|}{$\overline{\overline{E S}}$} & 0.2537 & \\
\hline \multicolumn{2}{|c|}{ Standar Deviasi } & 0.5442 & \\
\hline
\end{tabular}

Hasil analisis effect size pada Tabel 3 mengungkapkan bahwa secara keseluruhan rata-rata besar pengaruh penggunaan bahan ajar matematika atau yang dapat dikaitkan dengan bahan ajar matematika pada hasil publikasi penelitian-penelitian yang dianalisis dalam penelitian ini adalah sebesar 0,2537 dengan standar deviasi 0,5442. Terdapat 6 publikasi dengan interpretasi tinggi, 7 publikasi dengan interpretasi sedang, 10 publikasi dengan interpretasi rendah dan 4 publikasi dengan interpretasi terjadi penurunan. Hal tersebut menunjukkan bahwa terdapat dampak yang ditimbulkan oleh penggunaan bahan ajar matematika.

Berdasarkan karakteristik metodologi yang terdapat pada setiap publikasi yang dianalisis, maka pengaruh penggunaan bahan ajar matematika ditinjau dari karakteristik metodologi dapat disajikan dalam Table 4 sampai Tabel 7 berikut. Dimana $\mathrm{n}$ yang tertera dalam tabel mengindikasikan banyaknya publikasi.

Tabel 4. Karakteristik Metodologi pada Tahun Publikasi

\begin{tabular}{|c|c|c|c|c|c|}
\hline No. & $\begin{array}{c}\text { Tahun } \\
\text { Publikasi }\end{array}$ & $\mathbf{n}$ & $\sum E S$ & $\overline{E S}$ & $\begin{array}{c}\text { Standar } \\
\text { Deviasi }\end{array}$ \\
\hline 1 & 2016 & 2 & 0.7273 & 0.3636 & 1.0101 \\
\hline 2 & 2017 & 4 & 0.1269 & 0.0317 & 0.5880 \\
\hline 3 & 2018 & 3 & 1.1600 & 0.3867 & 0.1855 \\
\hline 4 & 2019 & 11 & 3.1840 & 0.2895 & 0.6700 \\
\hline 5 & 2020 & 7 & 1.6541 & 0.2363 & 0.3642 \\
\hline
\end{tabular}

Tabel 5. Karakteristik Metodologi pada Desain Penelitian

\begin{tabular}{|c|c|c|c|r|}
\hline $\begin{array}{c}\text { Desain } \\
\text { Penelitian }\end{array}$ & $\mathbf{n}$ & $\sum_{E S}$ & $\overline{E S}$ & $\begin{array}{c}\text { Standar } \\
\text { Deviasi }\end{array}$ \\
\hline Pengembangan & 10 & 3.4851 & 0.3485 & 0.2889 \\
\hline Eksperimen & 13 & 1.6447 & 0.1265 & 0.7271 \\
\hline PTK & 3 & 1.3059 & 0.4353 & 0.3005 \\
\hline Mix Method & 1 & 0.4165 & 0.4165 & \\
\hline
\end{tabular}

Tabel 6. Karakteristik Metodologi pada Kelompok Sampel

\begin{tabular}{|c|c|c|c|c|}
\hline $\begin{array}{c}\text { Kelompok } \\
\text { Sampel }\end{array}$ & $\mathbf{n}$ & $\sum E S$ & $\overline{E S}$ & $\begin{array}{c}\text { Standar } \\
\text { Deviasi }\end{array}$ \\
\hline SD & 7 & 0.7724 & 0.1103 & 0.7945 \\
\hline SMP & 4 & 0.3610 & 0.0903 & 0.3234 \\
\hline SMA/SMK & 5 & 1.0137 & 0.2027 & 0.6697 \\
\hline Mahasiswa & 10 & 4.3024 & 0.4302 & 0.3664 \\
\hline Guru & 1 & 0.4026 & 0.4026 & \\
\hline
\end{tabular}

Tabel 7. Karakteristik Metodologi pada Alat Pengukuran

\begin{tabular}{|c|c|c|c|c|}
\hline $\begin{array}{c}\text { Alat } \\
\text { Pengukuran }\end{array}$ & $\mathbf{n}$ & $\sum_{E S}$ & $\overline{E S}$ & $\begin{array}{c}\text { Standar } \\
\text { Deviasi }\end{array}$ \\
\hline Dikembangkan & 22 & 6.1575 & 0.2799 & 0.5278 \\
\hline Sudah ada & 5 & 0.6948 & 0.1390 & 0.6653 \\
\hline
\end{tabular}

Berdasarkan karakteristik instruksional yang terdapat pada setiap publikasi yang dianalisis, maka pengaruh penggunaan bahan ajar matematika ditinjau dari karakteristik instruksional dapat disajikan dalam Table 8 sampai Tabel 11 berikut.

Tabel 8. Karakteristik Instruksional pada Jenis Prestasi Matematika

\begin{tabular}{|c|c|c|c|c|}
\hline $\begin{array}{c}\text { Jenis Prestasi } \\
\text { Matematika }\end{array}$ & $\mathbf{n}$ & $\sum$ ES & $\overline{E S}$ & $\begin{array}{c}\text { Standar } \\
\text { Deviasi }\end{array}$ \\
\hline $\begin{array}{c}\text { Keterampilan } \\
\text { berpikir }\end{array}$ & 4 & 2.5544 & 0.6386 & 0.2977 \\
\hline Hasil belajar & 18 & 2.9686 & 0.1649 & 0.6154 \\
\hline $\begin{array}{c}\text { Pemecahan } \\
\text { masalah }\end{array}$ & 2 & 0.8083 & 0.4042 & 0.4253 \\
\hline Pemahaman & 1 & 0.2539 & 0.2539 & \\
\hline Metakognitif & 1 & 0.1966 & 0.1966 & \\
\hline $\begin{array}{c}\text { Keterampilan } \\
\text { Komunikasi }\end{array}$ & 1 & 0.0704 & 0.0704 & \\
\hline
\end{tabular}


Tabel 9. Karakteristik Instruksional pada Jenis Bahan Ajar

\begin{tabular}{|c|c|c|c|c|}
\hline $\begin{array}{c}\text { Jenis Bahan } \\
\text { Ajar }\end{array}$ & $\mathbf{n}$ & $\sum_{E S}$ & $\overline{E S}$ & $\begin{array}{c}\text { Standar } \\
\text { Deviasi }\end{array}$ \\
\hline $\begin{array}{c}\text { Berbasis } \\
\text { Komputer }\end{array}$ & 17 & 3.0434 & 0.3382 & 0.8681 \\
\hline Pisik & 7 & 2.8118 & 0.7029 & 0.8422 \\
\hline $\begin{array}{c}\text { Berbasis } \\
\text { komputer dan } \\
\text { pisik }\end{array}$ & 3 & 0.9971 & 0.4985 & 0.5826 \\
\hline
\end{tabular}

Tabel 10. Karakteristik Instruksional pada Pelaksana Penelitian

\begin{tabular}{|c|c|c|c|c|}
\hline $\begin{array}{c}\text { Pelaksana } \\
\text { penelitian }\end{array}$ & $\mathbf{n}$ & $\sum_{E S}$ & $\overline{E S}$ & $\begin{array}{c}\text { Standar } \\
\text { Deviasi }\end{array}$ \\
\hline Dosen & 25 & 5.5981 & 0.4306 & 0.5553 \\
\hline Guru & 2 & 1.2541 & 0.8361 & 0.00029 \\
\hline
\end{tabular}

Tabel 11. Karakteristik Instruksional pada Metode Penggunaan Bahan Ajar

\begin{tabular}{|c|c|c|c|c|}
\hline $\begin{array}{c}\text { Metode } \\
\text { Penggunaan } \\
\text { Bahan Ajar }\end{array}$ & $\mathbf{n}$ & $\sum_{E S}$ & $\overline{E S}$ & $\begin{array}{c}\text { Standar } \\
\text { Deviasi }\end{array}$ \\
\hline Individual & 5 & 2.8229 & 0.5646 & 0.3793 \\
\hline Berkelompok & 7 & 1.8988 & 0.2713 & 0.3193 \\
\hline $\begin{array}{c}\text { Individual dan } \\
\text { Berkelompok }\end{array}$ & 20 & 2.1305 & 0.1420 & 0.6460 \\
\hline
\end{tabular}

Melakukan eksplorasi terhadap pengaruh penggunaan bahan ajar dalam pembelajaran matematika adalah tujuan dari meta analisis ini. Pada konteks ini 27 penelitian dimasukkan dalam meta analisis dan dilakukan penghitungan effect size. Berdasarkan klasifikasi effect size Cohen dimana rata-rata nilai effect size pengaruh penggunaan bahan ajar matematika dalam pembelajaran adalah sedang dan positif. Demikian pula penelitian meta-analisis yang meneliti pengaruh penggunaan bahan ajar terhadap prestasi akademik dalam pelajaran geografi menemukan effect size yang positif dan besar(Singh dkk, 2016). Selain itu, sebuah penelitian yang meneliti pengaruh penggunaan bahan ajar gabungan antara digital dan pisik terhadap prestasi akademik pada pembelajaran social, sains dan matematika memiliki effect size positif dan sedang (Passolunghi dkk, 2020). Hasil penelitian ini sejalan dengan hasil penelitian Moraová (2017), Prendergast dkk (2017), dan Koparan (2017) tentang pengaruh penggunaan bahan ajar terhadap prestasi belajar dalam pelajaran matematika (Koparan, 2017; Moraová, 2017; Prendergast dkk, 2017). Penelitian metaanalisis tentang pengaruh penggunaan bahan ajar digital pada terhadap prestasi akademik, terutama dalam pembelajaran matematika, yang serupa dengan penelitian ini, penggunaan bahan ajar digital diidentifikasi efektif pada prestasi akademik. Penelitian tersebut dilakukan pada tahun 2017, dimana Byun dan Joung melakukan meta analisis dengan total 296 penelitian dikumpulkan untuk ditinjau, tetapi dari penelitian tersebut, hanya 33 penelitian yang diidentifikasi sebagai studi empiris dan secara sistematis dianalisis untuk menyelidiki tren penelitian saat ini (Byun \& Joung, 2018). Selain itu, karena data statistik yang tidak mencukupi, hanya 17 dari 33 studi yang dianalisis untuk menghitung effect size penggunaan game digital secara keseluruhan pada pembelajaran matematika. Hasil penelitian Byun dan Joung menunjukkan bahwa effect size keseluruhan adalah positif dan sedang dari pemanfaatan bahan ajar digital pada pembelajaran matematika secara numeric. Selain itu, meta-analisis tentang penggunaan bahan ajar pisik dalam pendidikan matematika menemukan pengaruh bahan ajar pisik terhadap prestasi akademik (Callaman \& Itaas, 2020). Selain itu, pengaruh juga ditemukan dari jenis bahan ajar digital terhadap prestasi akademik dalam pembelajaran matematika (Batdi \& Talan, 2019). Secara keseluruhan, penelitian ini menunjukkan bahwa effect size yang dihitung terkait dengan efek penggunaan bahan ajar dalam pembelajaran matematika terhadap prestasi akademik siswa adalah tinggi. Ketika semua hasil ini dipertimbangkan, maka dapat dikonfirmasi bahwa penggunaan bahan ajar dalam pembelajaran matematika memiliki efek positif.

Temuan lain dari meta-analisis ini adalah bahwa variabel moderator yang terkait dengan karakteristik metodologi tidak memiliki pengaruh moderasi yang signifikan. Jenis penelitian tidak mengubah pengaruh ukuran rata-ratanya terhadap prestasi akademik. Hasil ini bertentangan dengan Carbonneau dkk yang menemukan perbedaan yang signifikan antara desain penelitian (Carbonneau dkk, 2013). Hasil penelitian mereka menunjukkan bahwa effect size studi eksperimental semu lebih tinggi daripada effect size studi eksperimental. Perbedaan ini dapat dijelaskan karena proses belajarmengajar matematika yang dirancang sebagai pembelajaran eksperimental dan semi eksperimental yang berbeda satu sama lain. Meta-analisis ini menunjukkan bahwa perbedaan tingkat kelas siswa tidak mengubah ukuran pengaruhnya terhadap prestasi akademik. Hasil ini serupa dengan hasil penelitian Kablan dkk pada tahun 2013 (Kablan dkk, 2013). Studi mereka menunjukkan bahwa effect size tidak bervariasi menurut tingkat kelas. Variabel metodologis lain yang diselidiki untuk peran moderasi dalam penelitian ini adalah 'alat ukur'. Menurut hasil, variabel ini bukan moderator yang signifikan. Jadi, untuk tujuan menilai prestasi akademik, menggunakan alat ukur yang disiapkan oleh peneliti dari penelitian tersebut atau instrumen yang dikembangkan dalam penelitian lain tidak mengubah ukuran pengaruhnya terhadap prestasi akademik. Temuan terakhir dari penelitian ini adalah bahwa variabel yang terkait dengan karakteristik instruksional memiliki pengaruh moderasi yang signifikan terhadap prestasi akademik siswa. Variabel yang terkait dengan pembelajaran adalah jenis prestasi matematika, jenis bahan ajar, dan metode penggunaan bahan ajar. Perbedaan yang signifikan ditemukan antara variabel-variabel ini. Effect size jenis prestasi matematika dalam bentuk keterampilan berpikir lebih tinggi daripada effect size jenis prestasi matematika lainnya. Demikian 
pula, A juga menemukan bahwa effect size dari jenis prestasi matematika bervariasi. Berdasarkan hasil penelitian ini, dapat disimpulkan bahwa penggunaan bahan ajar matematika terhadap keterampilan berpikir memiliki efek yang lebih positif dalam pembelajaran dibandingkan dengan jenis prestasi matematika lainnya (Radovic dkk, 2020).

Variabel pembelajaran lain 'jenis bahan ajar', dengan kata lain menggunakan bahan ajar pisik atau digital atau menggunakan keduanya, mempengaruhi rata-rata effect size pada prestasi akademik. Pada penelitian yang menggunakan bahan ajar digital memiliki effect size yang positif dan tinggi. Namun, temuan ini bertentangan dengan meta-analisis sebelumnya yang dilakukan oleh Kablan dkk pada tahun 2013 (Kablan dkk, 2013). Mereka tidak menemukan perbedaan yang signifikan antara ukuran efek variabel mengenai jenis bahan ajar yang berbeda. Hasil belajar yang berbeda terkait dengan jenis bahan ajar ini dapat membantu kita memahami bahwa penggunaan jenis bahan ajar yang berbeda dalam pembelajaran matematika cukup penting untuk prestasi akademik siswa. Pada penelitian eksperimen, peneliti atau guru dapat menerapkan tes atau bahan ajar ke kelompok eksperimen atau kontrol dan topik dapat diajarkan oleh guru yang berbeda. Semua masalah ini dapat mempengaruhi prestasi akademik siswa. Selain itu, tingkat keterampilan manajemen kelas para peneliti dapat mempengaruhi hasil. Di sisi lain, ketika hanya peneliti yang mengelola proses pelaksanaannya, maka kegiatan belajar mengajar dapat dilaksanakan sebagaimana mestinya (Parmaxi \& Zaphiris, 2020). Dalam penelitian ini, 'pelaksana' dianalisis sebagai variabel moderator dan ditemukan bahwa effect size terhadap prestasi akademik tidak berubah ketika materi pendidikan digunakan oleh peneliti atau guru atau keduanya. Pada penelitian A ditemukan bahwa metode penggunaan bahan ajar secara individual dan berkelompok memiliki efek positif pada keberhasilan siswa. Namun, dalam penelitian ini metode penggunaan bahan ajar secara individual dalam pelajaran matematika memiliki effect size yang lebih tinggi dibandingkan dengan metode penggunaan bahan ajar lainnya.

\section{KESIMPULAN}

Penggunaan bahan ajar berpengaruh tinggi terhadap prestasi belajar matematika. Effect size pada karakteristik metodologi tidak begitu berpengaruh namun pada karakteristik instruksional sebagian besar memiliki pengaruh yang bervariasi. Bahan ajar digital terbukti lebih efektif dalam pencapaian matematika dibandingkan dengan jenis bahan ajar lainnya. Akibatnya, karakteristik instruksional harus dipertimbangkan saat merancang lingkungan belajar. Menurut hasil meta-analisis yang dilakukan untuk penelitian ini, penggunaan bahan ajar memiliki pengaruh yang kuat terhadap prestasi belajar matematika.

\section{SARAN}

Secara implikasi dan rekomendasi penelitian ini mendukung rasional bahwa penggunaan bahan ajar merupakan alternatif pembelajaran yang dapat meningkatkan prestasi belajar matematika siswa. Berdasarkan meta-analisis yang telah dilakukan menunjukkan adanya beberapa kekurangan. Sebagai tindak lanjut dari studi ini, rekomendasi yang dapat disarankan adalah untuk peneliti selanjutnya agar lebih meneliti ke jenjang-jenjang yang pengaruhnya kurang agar penggunaan bahan ajar matematika bermanfaat untuk semua jenjang pendidikan; dan ke jenis prestasi matematika lainnya agar penggunaan bahan ajar matematika bermanfaat untuk semua jenis prestasi matematika.

\section{DAFTAR PUSTAKA}

Alshehri, M. A., \& Ali, H. S. (2016). The Compatibility of Developed Mathematics Textbooks' Content in Saudi Arabia (Grades 6-8) with NCTM Standards. Journal of Education and Practice, 7(2), 137-142.

Baist, A., Fadillah, A., \& Nopitasari, D. (2019). Students Self Regulated Learning in Numerical Methods Course using Computational Mathematics Teaching Materials. Malikussaleh Journal of Mathematics Learning, 2(1), 1-4.

Basarmak, U. (2019). The Effect Of Digital Teaching Material (Public Service Ad) Development Process On Preservice Teachers' Creative Thinking Skills. Malaysian Online Journal of Educational Technology, 7(4), 126-144.

Batdi, V., \& Talan, T. (2019). Augmented Reality Applications: A Meta-Analysis and Thematic Analysis. Turkish Journal of Education, 8(4), 276297.

Burns, B., \& Hamm, E. (2011). A comparison of concrete and virtual manipulative use in third and fourth grade mathematics. School Science and Mathematics, 111(6), 256-261.

Byun, J., \& Joung, E. (2018). Digital game-based learning for K-12 mathematics education: A metaanalysis. School Science and Mathematics, 1-14.

Callaman, R. A., \& Itaas, E. C. (2020). Students' Mathematics Achievement in Mindanao Context: A Meta-Analysis. Journal of Research and Advances in Mathematics Education, 5(2), 148159.

Carbonneau, K. J., Marley, S. C., \& Selig, J. P. (2013). A meta-analysis of the efficacy of teaching mathematics with concrete manipulatives. Journal of Educational Psychology, 105(2), 380-400.

Chen, C.-H., \& Su, C.-Y. (2019). Using the BookRoll EBook System to Promote Self-Regulated Learning, Self-Efficacy and Academic Achievement for University Students. Educational Technology \& Society, 22(4), 33-46.

Demirkan, O. (2019). Pre-service Teachers' Views about Digital Teaching Materials. Educational Policy 
Analysis and Strategic Research, 14(1), 1-22.

Dewi, N., Magfiroh, L., Nurkhalisa, S., \& Dwijayanti, I. (2019). The Development of Contextual-Based Science Digital Storytelling Teaching Materials to Improve Students' Critical Thinking on Classification Theme. Journal of Turkish Science Education, 16(3), 364-378.

Gozuyesil, E., \& Tanriseven, I. (2017). A Meta-analysis of the Effectiveness of Alternative Assessment Techniques. Eurasian Journal of Educational Research, 70, 37-56.

Hornburg, C. B., Shipley, H. B., Matthews, J. M., \& McNeil, N. M. (2021). Improving Understanding of Mathematical Equivalence. Mathematics Teacher: Learning and Teaching PK-12, 114(1), 16-26.

Kablan, Z., Topan, B., \& Erkan, B. (2013). The effectiveness level of material use in classroom instruction: a meta-analysis study. Educational Sciences: Theory \& Practice, 13(3), 1629-1644.

Karakırık, E., \& Aydın, E. (2016). Matematik nesneleri ve sanal manupulatifler. [Learning objects and virtual manipulatives] (E. Doğan, M ve Karakırık (ed.); Matematik). Nobel-Atlas Yayıncılık.

Kontaş, H. (2016). The Effect of Manipulatives on Mathematics Achievement and Attitudes of Secondary School Students. Journal of Education and Learning, 5(3), 10-20.

Koparan, T. (2017). Analysis of Teaching Materials Developed by Prospective Mathematics Teachers and Their Views on Material Development. Malaysian Online Journal of Educational Technology, 5(4), 8-28.

Kraft, M. A. (2020). Interpreting Effect Sizes of Education Interventions. Educational Researcher, 49(4), 241-253.

Kraft, M. A., \& Hattie, J. (2021). Interpreting Education Research and Effect Sizes. Educational Leadership, 78(8).

Kreijns, K., Vermeulen, M., Buuren, H. V., \& Acker, F. V. (2017). Does Successful Use of Digital Learning Materials Predict Teachers' Intention to Use Them Again in the Future? International Review of Research in Open and Distributed Learning, 18(7), 158-174.

Lei, Q., Mason, R. A., Xin, Y. P., Davis, J. L., David, M., \& Lory, C. (2020). A Meta-Analysis of SingleCase Research on Mathematics Word ProblemSolving Interventions for English Learners with Learning Disabilities and Mathematics Difficulties. Learning Disabilities Research \& Practice, 35(4), 201-217.

Lorah, J. (2018). Effect Size Measures for Multilevel Models: Definition, Interpretation, and TIMSS Example. Large-Scale Assessments in Education, 6(8), 1-11.

Maggin, D. M., Cook, B. G., \& Cook, L. (2019). Making Sense of Single-Case Design Effect Sizes.
Learning Disabilities Research \& Practice, 34(3), 124-132.

Márquez, N. L. N., Baldominos, A., \& Nieto, M. Á. P. (2020). Digital Teaching Materials and Their Relationship with the Metacognitive Skills of Students in Primary Education. Education Sciences, 10(113), 1-18.

Mavridis, D., \& White, I. R. (2020). Dealing with Missing Outcome Data in Meta-Analysis. Research Synthesis Methods, 11(1), 2-13.

Miller, J. L., Wilson, K., Miller, J., \& Enomoto, K. (2017). Humorous Materials to Enhance Active Learning. Higher Education Research and Development, 36(4), 791-806.

Moraová, H. (2017). Do Authors of Online Electronic Materials for Teaching Mathematics use Their Potential to use Non-Stereotypical Cultural Settings? The Electronic. Journal of e-Learning, 15(3), 235-243.

Mughaz, D., Cohen, M., Mejahez, S., Ades, T., \& Bouhnik, D. (2020). From an Artificial Neural Network to Teaching. Interdisciplinary Journal of E-Skills and Lifelong Learning, 16, 1-17.

Mutmainah, Rukayah, \& Indriayu, M. (2019). Effectiveness of experiential learning-based teaching material in Mathematics. International Journal of Evaluation and Research in Education, $8(1), 57-63$.

Ng, O.-L., \& Chan, T. (2018). Learning as Making: Using 3D computer-aided design to enhance the learning of shape and space in STEM-integrated ways. British Journal of Educational Technology, $1-15$.

Nyarko, E. A., Agyei, D. D., \& Armah, J. K. (2020). Digitizing distance learning materials: Measuring students' readiness and intended challenges. Education and Information Technologies, 25, 2987-3002.

Özcan, H., \& Koştur, H. (2019). Analyzing Pre-service Science Teachers' Physics Materials. Science Education International, 30(1), 21-27.

Packenham, P. M., \& Suh, J. (2012). Learning mathematics with technology: The influence of virtual manipulatives on different achievement groups. Journal of Computers in Mathematics \& Science Teaching, 112(3), 133-146.

Park, J. (2019). Supporting Maintenance in Mathematics Using the Virtual-Representational-Abstract Instructional Sequence Intervention Package. ProQuest Dissertations Publishing.

Parmaxi, A., \& Zaphiris, P. (2020). Lessons Learned from a Design-Based Research Implementation: A Researcher's Methodological Account. International Journal of Research \& Method in Education, 43(3), 257-270.

Passolunghi, M. C., Vita, C. D., \& Pellizzoni, S. (2020). Math Anxiety and Math Achievement: The Effects of Emotional and Math Strategy Training. 
Developmental Science, 23(6), 1-11.

Prendergast, M., Spassiani, N. A., \& Roche, J. (2017). Developing a Mathematics Module for Students with Intellectual Disability in Higher Education. International Journal of Higher Education, 6(3), 169-177.

Radovic, S., Radojicic, M., Veljkovic, K., \& Maric, M. (2020). Examining the Effects of GeoGebra Applets on Mathematics Learning Using Interactive Mathematics Textbook. Interactive Learning Environments, 28(1), 32-49.

Rikkerink, M., Verbeeten, H., Simons, R.-J., \& Ritzen, H. (2016). A New Model of Educational Innovation: Exploring The Nexus of Organizational Learning, Distributed Leadership, and Digital Technologies. Journal of Educational Change, 17, 2.

Samartsidis, P., Montagna, S., Laird, A. R., Fox, P. T., Johnson, T. D., \& Nichols, T. E. (2020). Estimating the Prevalence of Missing Experiments in a Neuroimaging Meta-Analysis. Research Synthesis Methods, 11(6), 866-883.

Sentürk, C., \& Zeybek, G. (2019). Teaching-Learning Conceptions and Pedagogical Competence Perceptions of Teachers: A Correlational Research.
Research in Pedagogy, 9(1), 65-80.

Singh, S. S. B., Rathakrishnan, B., Sharif, S., Talin, R., \& Eboy, O. V. (2016). The Effects of Geography Information System (GIS) Based Teaching on Underachieving Students' Mastery Goal and Achievement. Turkish Online Journal of Educational Technology, 15(4), 119-134.

Soykan, E., Gemikonakli, E., \& Kanbul, S. (2019). Examination of Designed Materials in Digital Environment on Concept Teaching in Special Education. International Journal of Disability, Development and Education, 66(5), p. 550. Bosco, A., Santiveri, N., \& Tesconi, S. (2019). Digital Making in Educational Projects. Center for Educational Policy Studies Journal, 9(3), 541-550.

Ünlü, M. (2017). Pre-service mathematics teachers' views about using instructional materials in mathematics lessons. Journal of Theory and Practice in Education, 13(1), 10-34.

Zwart, D. P., Luit, J. E. H. V., Noroozi, O., \& Goei, S. L. (2017). The effects of digital learning material on students' mathematics learning in vocational education. Cogent Education, 4, 1-10. 